\title{
Halkla İliş̧kiler Ajansları için Bulut Tabanlı Güvenli Çok Taraflı Hesaplama ve İş Birliği Servisi - SMPCCaaS
}

\author{
Şaha Burcu Baygül Özpınar ${ }^{1 *}$, Alper Özpınar ${ }^{2}$ \\ 1* Üsküdar Üniversitesi, İletişim Fakültesi, Halkla İlişkiler ve Tanıtım, İstanbul, Türkiye, (ORCID: 0000-0001-6374-0354), saha.ozpinar@uskudar.edu.tr \\ 2 İstanbul Ticaret Üniversitesi, Mühendislik Fakültesi, Mekatronik Mühendisliği Bölümü, İstanbul, Türkiye, (ORCID: 0000-0003-1250-5949), aozpinar@ticaret.edu.tr
}

(İlk Geliş Tarihi 23 Ekim 2021 ve Kabul Tarihi 12 Aralık 2021)

(DOI: 10.31590/ejosat.1013962)

ATIF/REFERENCE: Baygül Özpınar, Ş. B. \& Özpinar, A. (2021). Halkla ilişkiler ajansları için bulut tabanlı güvenli çok taraflı hesaplama ve işbirliği servisi - SMPCCAAS. Avrupa Bilim ve Teknoloji Dergisi, (31), 783-790.

\section{Öz}

Günümüzde veriye erişebilmek ve bu veriyle yapılabileceklerin farkında olmak her sektörde kurumlar için büyük önem taşımaktadır. Halkla ilişkiler alanında da veri kavramı merkezi konumdadır. Halkla ilişkiler uzmanları, bir kurum, marka, ürün, kavram veya birey hakkında genel halkın ya da hedef kitlelerin algısını etkilemek için gerçek verileri kullanmaktadır. Uzmanlar farklı kaynaklardan elde edilen verilerle bilgilere ulaşabilmekte ve bunları analiz ederek daha doğru kararlar alabilmektedir. Kaliteli veri hizmete değer katmaktadır. Bu nedenle halkla ilişkiler ajansları ve uzmanları bu konudaki teknolojileri takip etmek ve hızla benimsemek durumundadır. Veriye ulaşmanın tek yolu birincil ya da ikincil araştırmalar değildir. Bu çalışmada son yıllarda büyük ilgi görmeye başlayan güvenli veri paylaşımı konusunun halkla ilişkiler alanındaki yansımaları ele alınmaktadır. Bilginin değerinin giderek arttığı bir çağda halkla ilişkiler ajanslarının güvenli veri işleyebilmesi için bulut tabanlı, güvenli ve çok taraflı bir hesaplama ve iş birliği servisinin kullanılabilirliği tartışılmakta ve bir sistem önerisi sunulmaktadır. Bu makale böyle bir sistemin halkla ilişkilerde kullanımını içeren ilk çalışma olarak alana ve alan yazına katkıda bulunmayı hedeflemektedir. Güvenli çok taraflı hesaplama ve gizliliği koruyan hesaplama yaklaşımları halkla ilişkiler faaliyetleri için önemli bir potansiyel sunmaktadır.

Anahtar Kelimeler: Halkla İlişkiler, Veri Yönetişimi, Bulut Bilişim, Güvenli Çok Taraflı Hesaplama, Homomorfik Şifreleme, Veri Gizliliği

\section{Cloud Based Secure Multi Party Computing and Collaboration Service for Public Relations Agencies - SMPCCaaS}

\begin{abstract}
Today, access to data and to know what can be done with it is of great importance for all institutions. Data is also central in the field of public relations. Public relations professionals use real data to influence the perception of the public or target audiences about an institution, brand, product, concept or individual. Experts can access information with data obtained from different sources and can make more accurate decisions by analyzing them. The use of quality data adds value not only to the corporate image, but also to the service of experts who use it. For this reason, public relations agencies and experts must follow and rapidly adopt the technologies in this field. Primary or secondary research is not the only way to access data. This study deals with the reflections of secure data processing in the field of public relations. In an era where the value of information is increasing, this study discusses the availability of a cloudbased, secure, and multilateral computing and collaboration service, and proposes a system for public relations agencies to share data securely. This article aims to contribute to the field and the literature as the first study involving the use of such a system in public relations. Secure multilateral computing and private computing approaches offer significant potential for public relations activities.
\end{abstract}

Keywords: Public Relations, Data Governance, Cloud Computing, Secure Multi Party Computation, Homomorphic Encyrption, Privacy Preserving

\footnotetext{
*Sorumlu Yazar: saha.ozpinar@uskudar.edu.tr
} 


\section{Giriş}

İlki 1800'lerin sonlarına doğru başlayan sanayii devrimleri sonrasında gelen teknolojik gelişmeler, küçük işletmeleri geliştirerek büyük şirketlere dönüşmelerini sağlamıştır. 1900'lü yıllarda eski ekonomi olarak tanımlanan bir iş modeli içerisinde, şirketler için en önemli kavram üretim olmuş (Laudon ve Laudon, 2011), üretimi artırma ve arzın çok üzerinde olan talebe cevap verme amacı güdülmüştür. $\mathrm{Bu}$ dönem sermayenin yükselip büyüdüğü dönem olarak bilinmektedir. İlerleyen yıllarda, savaş ekonomilerinin etkilerinin azalıp yok olması, üretim teknolojilerinin gelişmesi ve sanayii devrimlerinin gerçekleşmesi sonucu üretim büyük sermaye gruplarının tekeli olmaktan çıkmış ve rekabet farklı bir alana doğru kaymıştır.

$\mathrm{Bu}$ yıllarda artan arz ile müşteri kavramı değer kazanmış, sadece ihtiyaca yönelik ürün ve hizmet üretmek değil bunları tanıtıp tutundurmak da önemli hale gelmiştir. İlerleyen yıllarda müşteri ile iletişim kurmak, ilişki yönetimi, sosyal pazarlama ve halkla ilişkiler gibi kavramlar şirketlerin stratejileri içerisinde giderek daha fazla yer bulmaya başlamıştır. Özellikle 1950'li yıllardan sonra halkla ilişkiler şirketler için üretmek kadar önemli bir kavram; stratejik bir iş süreci haline gelmiştir. $\mathrm{Bu}$ alanda literatürde yapılmış birçok çalışma ve mihenk taşı olarak tanımlanabilecek eser bulunmaktadır (Grunig ve Grunig, 1992; Harrison, 1953; Seitel, 2017; Wilcox et al., 2006) Tüm tarihsel ve toplumsal gelişmeler ile yeni ekonomik düzenlerin oluşması neticesinde, halkla ilişkiler ajansları da kendi evrimlerini geçirmek zorunda kalmışlardır. Bu evrimin tetikleyicisi doğal olarak, yeni koşullarda çalışmaya başlayan ve halkla ilişkiler ajanslarının müşterisi olan şirketlerdir. Ajans müşterilerinin halkla ilişkiler kavram ve süreçlerine olan bakışları, yeni stratejilere, yöntem ve tekniklere duydukları ihtiyaç, ajansların teknolojik gelişmeleri takip etmelerini ve hızla benimsemelerini gerektirmektedir.

Halkla ilişkiler giderek daha fazla veri odaklı hale gelmektedir. Dünyada halkla ilişkiler sektöründe, büyük veri giderek daha fazla benimsenmekte, verinin iyi uygulamaların temeli olmasına çalışılmaktadır. Veriye ulaşmak, paylaşmak ve kullanmak bir planlama gerektirir. Bu çalışmada 2010'lu y1llardan bu yana tartışılan ancak 2020'den itibaren daha büyük ilgi görmeye başlayan güvenli veri paylaşımı konusunun halkla ilişkiler alanındaki yansımaları ele alınmaktadır. Bilginin değerinin giderek arttığı bir çağda halkla ilişkiler ajanslarının güvenli veri paylaşımı yapabilmesi için bulut tabanlı, güvenli ve çok taraflı bir hesaplama ve iş birliği servisinin kullanılabilirliği tartışılmakta ve bir sistem önerisi sunulmaktadır.

\section{Halkla İlişiler ve Verinin Önemi}

Günümüzün halkla ilişkiler yaklaşımını anlamak için kavramın tarihi gelişimini anlamak önem taşısa da halkla ilişsiler hakkında kısa bir tarihçe yazılması gerektiğinde nereden başlanacağı bir sorun teşkil etmektedir. Cutlip (1994) alanın kökenlerinin kesin bir tarihle belirlenemeyeceğini, çünkü zaman içinde (ve farklı coğrafyalarda) bir dizi olayla geliştiğini açıklamaktadır. Bununla birlikte çoğu kaynak halkla ilişskiler mesleğinin başlangıcını 1900 ortalarında Boston'da "The Publicity Bureau" yani "Tanıtım Bürosu" adlı ajansın kurulmasıyla bağdaştırmaktadır. Halkla ilişkilerin babası olarak kabul edilen Ivy Lee'nin de aralarında olduğu bir grup eski e-ISSN: 2148-2683 gazeteci tarafindan kurulan bu ajansa kadar halkla ilişkilerin profesyonel bir alan olarak tanınmadığına dair ortak görüşlerden söz edilebilmektedir. Tarihçi Eric Goldman'a (1948, akt. Brown, 2010) göre, ilk sanayii devrimini takip eden 1900'lerin başındaki ilerleme döneminin şirket karşıtı ve reform yanlısı tutumu, kâğıt maliyeti düştükçe tirajı önemli ölçüde artan gazetelere yansımıştır. 1903'ten 1909'a kadar birçok gazete ve dergide bazı şirketlerin halkı ve hissedarlarını nasıl kandırdığını, siyaseti nasıl yozlaştırdığını, maaş ve vergi sistemlerindeki yanlışlarını anlatan detaylı ve öfkeli makaleler yayınlanmıştır. Halk, şirketlere karşı kızgın ve eleştirel hale gelmiştir. Halkla ilişkiler bu dönemde sansasyonel ve aşırı eleştirel haber makalelerine karşı kurumsal çıkarları savunma görevini üstlenerek popülerlik kazanmıştır. 1906'da Ivy Lee, halkla ilişkiler faaliyetlerinin açık ve şeffaf olması, gerçekleri içermesi ve kamuyu ilgilendiren konuları kapsaması gerektiğini söyleyen bir İlkeler Bildirgesi yayınlamış (Özgen ve Bilbil, 2007), bu bildirge halkla ilişkilerin, kamuoyunu yanıltmayı değil bilgilendirmeyi amaçlayan bir süreç olduğunu vurgulayan önemli bir başlangıç olmuştur.

Edward Bernays, 1920'lerdeki kuramsal çalışmaları nedeniyle yine bazı kaynaklar tarafından halkla ilişkilerin babası ve mesleğin ilk teorisyeni olarak anılmaktadır. Halkla ilişkiler üzerine ilk kitabı yazmış ve 1923 'te New York Üniversitesi'nde ilk dersi vermiştir. Ancak Bernays'in alana belki de en büyük katkısı bugün anladığımız anlamdaki halkla ilișkilerin en önemli özelliği olan iki-yönlü iletişim modelini halkla ilişkiler dünyasına tanıtmak olmuştur. Daha sonra Grunig ve Hunt (1984) tarafından “iki yönlü asimetrik model” olarak isimlendirilecek olan bu halkla ilişkiler modeli, iki yönlü ikna edici iletișimi savunmuştur. Kilit paydaşların tutum ve eylemlerini etkilemek için ikna edici iletişimi kullanmaktadır. Model hedef kitleleri tanımak, tutumlarını anlamak ve ikna etmek (bilgi, tutum ve davranış değișiklikleri yaratmak) için araştırma tekniklerini kullanmakta ve bu amaçla kaynak ve alıcı arasındaki ileri geri iletişimi düzenlemektedir. Halkla ilişkilerin önemli kuramcılarından olan Grunig daha sonra "iki yönlü simetrik model"i sunarak alana büyük bir katkıda bulunmuştur. Kuramcı halkla ilişkiler uygulamalarının ne olabileceğini ve ne olması gerektiğini yeniden tanımlayan normatif bir halkla ilişkiler pratiği kavramı sunduğu için bu modeli, teorik modellerin en gelişmişi olarak önermiştir. Buna göre halkla ilişkiler Bernays'in (1952) adlandırdığı şekli ile ikna edici yönetim modeline değil gerek kurum gerekse halkları için adalet dengesi ile tanımlanan tamamen yeni bir modele göre yapılmalıdır. Bu model, bir kuruluş ile kilit paydaşları arasında karşılıklı olarak yararlı ilișkiler yaratan ve sürdüren diyaloga odaklanmaktadır (Brown, 2010). Halkla ilişkilerin tarihsel gelişimi bugünkü modern yaklaşımın oluşmasında önemli etkiye sahiptir. 20. Yüzyılın başında medya ilişkileri ile doğan ve gelişen, daha sonra sırasıyla kamuoyunu bilgilendirmeye ve farklı bilimsel ikna yöntemlerine odaklanan halkla ilişkiler bugün sadece ikna etme değil, kurum ve paydaşları arasında anlamlı ilişkiler, güven ve bağ kurma amacı gütmektedir. Bugünün halkla ilişkiler anlayışında uygulayıcılar müzakerecilerdir. İletişim, yalnızca bir şirket için değil ilgili tüm tarafların yani tüm sosyal paydaşların faydalanması için kullanılmaktadır. Bugün Amerika Halkla İlişkiler Derneği (PRSA) terimi "kuruluşlar ve halkları arasında karşılıklı yarar sağlayan ilişkiler kuran stratejik bir iletişim süreci” olarak tanımlamaktadır (PRSSA, t.y.).

Sanayii devrimleri ve takip eden teknolojik gelişmeler üretimin artmasına ve yaygınlaşmasına yol açmış, arz talep arasındaki dengenin ters yönde değişmesi yeni bilgi ekonomisinin oluşmasında rol oynamıştır. Bilgi ekonomisi tüm sektörleri 
etkilediği gibi halkla ilişkiler alanını da etkilemektedir. Bilginin değerinin artması, 1980'lerde kişisel bilgisayarların sayısının artması ile dijital verinin oluşmasına neden olmuş sonrasında 2000 yıllardan sonra internetin yaygınlaşması ve hızlanmasıyla yeni nesil bir yaklaşıma dönüşmüştür. Üretimin yerini teknoloji ve bilgiye bıraktığı yeni nesil "nokta.com" şirketleri olarak da bilinen, fikri ve mülki hakları dijital ürünler olan şirketler tüm iş dünyasında ciddi bir dönüşüm yaşatmıştır (Ljungqvist ve Wilhelm Jr, 2003). Tuğlalardan ve fiziksel fabrikalardan oluşan ekonomi yerini dijital verilerden ve bilgisayarlardaki kliklerden oluşan yeni ekonomiye bırakmıştır (Kacen et al., 2013). Şirketlerin internet üzerinden satışları ve müşteri iletişimleri bu yaklaşıma göre şekillenmiştir (Ofek et al., 2011). Bu değişim o kadar büyük ve etkili olmuştur ki eski ekonominin liderleri ve kural koyucuları günümüzde sunucular ve bilgi sistemlerinden oluşan büyük ölçekli KOBİ seviyesindeki şirketlerin piyasa değerlerinin altına düşmüştür. 2000'li yıllarda en büyük piyasa değerine sahip olan petrol ve finans şirketleri yerlerini bilgi odaklı şirketlere bırakmışlardır. Bunun en dikkat çeken örneği John D. Rockefeller tarafindan 1870'lerde kurulan, sonrasında Exxon Mobil'a dönüşen Standard Oil isimli şirketin 138.9 milyar dolarlık piyasa değerinin bir online video konferans şirketi olan Zoom Video tarafından 139 milyar dolarlık piyasa değeri ile geçilmesi olmuştur (Fox, 2021). Bu durum anonimleşmiş olan "Veri, yeni petroldür" ifadesinin neden doğru olduğunun bir örneğidir (Hirsch, 2013).

Verinin önemli stratejik bir kaynak haline gelmesi 1900'lü yıllardan itibaren şirketlerin ve dünya politikasının petrole ve petrol ürünlerine dayalı üretim, imalat ve enerji üretimi süreçlerinde değişime yol açmıştır. Dijital bir varlık olan veri, petrol gibi fiziksel bir varlıktan yapısal olarak farklıdır ancak kavramsal olarak birçok benzerlik içermektedir. Ham petrol yeraltında olduğu sürece çok kıymetli değildir, uygun bir yöntemle çıkarıldığında ve sonrasında işlenerek farklı alt ürünlere dönüştüğünde ekonomik değeri artmaktadır. Bu alt ürünlerin hepsi aynı ekonomik değere sahip değildir. En kıymetli olanlar saflaştırma sonucu ortaya çıkan uçucu gazlar, uçak yakıtları, benzin ve solventlerdir. Sonrasinda üretilen hantal karbon moleküllerinden oluşan asfalt zift gibi ürünlerin değeri göreceli olarak çok daha düşüktür.

Benzer şekilde veri de bilgiye; yani işlenmiş ekonomik değere dönüştüğünde ekonomik değeri ve etkisi artmaktadır (Kim, 2001). Petrolden farklı olarak veri basitçe ve dünyanın her yerinde aynı yöntemlerle saflaştırılıp anlamlaştırılamaz; her veri kaynağ 1 ya da veri seti tek başına bilgiye dönüşmek için yeterli de olmayabilir. Büyük, gizli ve ham veri gruplarını birer faydalı bilgiye dönüştürme ve sonrasında analizlerini yapma işlemi, otomatik olarak programlar ve teknikler ile yapılmakta ve teknolojinin de verdiği yetkiye dayanarak pek çok alana fayda sağlamaktadır (Taşçı ve Şamlı, 2020, s.89). Veriler birleştikçe, istatistik, veri madenciliği, yapay zekâ, makine öğrenmesi ve derin öğrenme gibi güncel işleme teknikleri ile anlamlı hale getirildiğinde ekonomik değeri artmaktadır. Özetle veri dünyanın yeni iş yapma ve yürütme stratejilerini şekillendirmiştir. Teknik olarak doğru hammadde tedariği süreçlerinden başlayan, tam zamanında doğru yerde üretim, doğru fiyatlandırma ve doğru dağıtım artık kurumların ne varlığını ne de kârlılığını garantilemektedir. Kurumlar hedef kitlelerinin istek, ihtiyaç ve beklentilerini araştırmalar yoluyla tespit etmeli, rakiplerinden farklı ürün, hizmet ve deneyimler sunmalıdır. Buna ek olarak bireylerin istek ve ihtiyaçları ile toplumun iyiliği ve refahı arasında bir denge bulmalı, arzu ve ihtiyaçlara cevap verirken toplumun beklentilerini de göz önünde bulundurulmalıdır. Kurumların ürün ve hizmetlerinin nicel olarak üstün olması pazarda iyi bir oyuncu olmaları için artık yetersizdir; halkla ilişkiler hizmetlerinde önemli bir boyut olarak konumlanan ve kurumların daha fazla değer sağladığı algısını güçlendiren kurunmsal itibar çok çeşitli akademik disiplinlerin ilgisini de çekmiş ve büyüyen bir odak noktası haline gelmiştir (Barnett et al., 2006; Chun, 2005; Gotsi ve Wilson, 2001). Halkla ilişkiler ajanslarının ve uzmanların üstlendiği iş ve görevler yeni nesil iş anlayışlarıyla birlikte artmakta ve çeşitlenmektedir. Günümüzde halkla ilişkiler çalışmaları yeni nesil iş çevreleri ve ekonomik koşullar içerisinde şirketlerin var oluş nedenleri, kurum kültürü, felsefesi; ürün, hizmet ve faaliyetleri ile ilgili kamuoyunu bilgilendirme, tutum ve davranış değiştirme, farkındalık ve algıda seçicilik amaçlı çalışmalar, sevilen, güvenilen bir marka olmak için sosyal sorumluluk faaliyetleri, pazarlama amaçlı halkla ilişkiler ve sosyal medya yönetimi, şirketin hedefleri, vizyon ve misyonuna göre hedef kitlelerin ve paydaşların beklentilerine uyumlu her türlü faaliyetin tanımlanması ve yürütülmesine yönelik basılı, görsel ve dijital faaliyetleri içermektedir (Newsom et al., 2012). Tüm halkla ilişkiler çalışmaları için bilgiye dayalı süreçler tanımlamak ve sürdürmek iş süreçlerinin önemli bir parçasıdır (Kiousis et al., 2007).

Halkla ilişkiler ajanslarının, hizmet verdikleri şirketlerin hedef kitlelerini oluşturan bireyler artık kurumların kendileriyle kurdukları iletişimde pasif, sadece gönderilen mesajları alan ve buna göre hareket eden kişiler olmaktan çıkmış, her türlü veriyi takip eden aynı zamanda kendi verisini üreten kaynaklar haline gelmiştir. Bu bireyler dijital iletişim kanallarını, ürünler ve servisler hakkında verilenden daha fazla bilgi almak için kullanmaktadırlar. Üstelik bireylerin ulaşabildikleri şirketlerin sadece hangi ihtiyaca ne tür bir ürün ya da servisle cevap verdikleri bilgisini değil; ürünler ilgili teknik bilgiler, karşılaştırmalı yorumlar, beğeniler ve şikayetlere göre diğer tüketicileri ne kadar tatmin edip etmediği, yasal ya da ahlaki olmayan faaliyetlerde bulunup bulunmadı̆̆ 1 ; kendisine, ailesine, çevresine ve içinde yaşadığı topluma başka şekillerde de hizmet edip etmediğini kapsamaktadır (Baygül Özpınar, 2015). Ürün ve hizmetler arasındaki rekabet, bireylerin özellikle dijital hizmet ve ürünleri çok hızlı değiştirebilmesi, bir ürün ve hizmetten diğerine kolaylıkla transfer olmasina neden olmakta, benzer ürün ve hizmetlerde, seçme kriterine yeni boyutlar eklemektedir (Whitten ve Leidner, 2006). Dolayısı ile yeni iletişim teknolojileri kurumlar tarafindan ne kadar erken ve hızlı uygulanırsa o kadar büyük rekabetçi avantaj sağlamaktadır. (Baygül Özpınar, 2021.)

Günümüzde üretilen veri artık sayılar ile ifade edildiğine içerdiği sıfırlar ve büyüklükleri nedeni ile anlaması zor terimler ile ifade edilmektedir. Bilgi teknolojileri dünyasının veri boyutu olan ve sekiz bitin bir araya gelerek oluşturduğu en temel veri bileşeni olan byte kavramından on üzeri onsekiz byte anlamına gelen exabyte yada matematiksel olarak kentilyon (quintillion) olarak tanımlanan sosyal medyadaki her paylaşım ve beğeniden, GSM şirketlerinin görüşme ve konum bilgisi kayıtlarına, uzayda kendi başına yol almakta Voyager uzay aracının verilerine kadar birçok farklı veriyi içermektedir. Bu veriler yaklaşık 2.5 exabyte seviyesine ulaşmıştır (Bulao, 2021). Nesnelerin interneti, giyilebilir sensörler, online platformlar üzerinde her insan yada halkla ilişkiler anlamında hedef kitle günlük ortalama 1.7 Megabyte veri üretmektedir.

$\mathrm{Bu}$ boyutta üretilen veriler geleneksel kurum içi veri saklama ve işleme sistemleri ile yönetilemeyecek kadar büyümüş, saklamak ve işleme için özel donanım, yazılım ve süreçlere 
ihtiyaç duyar hale gelmiştir. 2000'li yıllarda sadece ilişsisel verilerden oluşan düzenli verilerin oluşturduğu veri ambarlarından günümüzde ilişkisel, nesne tabanlı, yapılandırılmış, yarı yapılandırılmış veri göllerine dönüşmüştür. Artık her türlü verinin şirketlerin yönetimsel süreçlerinde kullanıldı̆̆ bir yapıya kavuşmuştur. (Baars ve Kemper, 2008) Büyük veri, genel olarak $5 \mathrm{~V}$ olarak da bilinen beş boyuttan oluşmaktadır. Bunlar çeşitlilik (variety), hız (velocity), hacim (volume), doğruluk (veracity) ve değer (value) olarak tanımlanmaktadır (Demchenko et al., 2014; Zhang et al., 2017). Büyük veri kavramı ilk konuşulmaya başladığı ve sanallaştırma sistemlerinin bulut bilişim kavramının temellerine attığ 2010 yılından sonra gelişmiştir. Büyük veri, neredeyse her dijital dönüşümün merkezinde kabul edilmeye başlanmış kuruluşlar, bireyler, işletmeler, topluluklar ve hükümetler için çok önemli olduğu vurgulanmıştır. (Manyika et al., 2011) Ancak verinin kim için ne ifade ettiği ve kullanıldığı konusu kavramsal modelin ötesinde uygulama hemen geçememiştir. Hatta ilk y1llar tamamen teknik olarak ele alınmış olan büyük veri kavramı sektördeki teknoloji firmaları tarafından donanımsal altyapı olarak konumlandırılmıştır. IBM firması büyük veri ile ilgili yaptığı çalışmalarda büyük veriyi değer( value) kavramı olmadan 4V olarak tanımlamıştır. (Wang, 2014) İlerleyen yılları içerisinde sadece verinin dijital bir varlık olmasının yeterli olmadığı bu varlığın değerinin de önemli olduğu ortaya çıkmış ve büyük veri günümüzde $5 \mathrm{~V}$ olarak tanımlanır hale gelmiştir. Büyük veri ve bu verinin işlendiği tutulduğu bulut bilişim kavramları hayatımızın her aşamasında konumlanır hale gelmiştir.

Halkla ilişkiler konusu da teknolojinin ve verinin önlenemez yükselişi ve yeni nesil iş yapma modelleri sonucunda yeni nesil $5 \mathrm{~V}$ verilerini kullanabilecek bir yapılanma ihtiyacı ile karşı karşıya kalmıştır. Dolayısı ile büyük veri tüm diğer alanlarda olduğu gibi halkla ilişkiler alanında da süreçleri ve stratejileri değişime uğratmıştır (Mark Weiner, 2016).

Geleneksel anlamda sınırlı veri ile iletişim süreçlerini planlanması, uygulanması ve kontrolü yeni bir konu değildir (Johnson, 1997). Ancak gerek kişisel verilerin korunması ile ilgili düzenlemeler ve bireylerin tercihleri, siber güvenlik yaklaşımları verilerden bilgi üretilmesi, büyük verinin halkla ilişkiler süreçlerinde kullanılması, tüm bu değişim ve gereksinimleri optimize ederek ekosistemdeki tüm paydaşlar için ergonomik ve kullanılabilir olmasını sağlamak zorlu ve karmaşık bir süreç olarak karşımıza çıkmaktadır (Wiencierz ve Röttger, 2019).

Halkla ilişkiler ve kurumsal iletişim ajanslarındaki veriler genel olarak öz kaynaklar ile üretilmiş olan pazarlama iletişimi faaliyetleri verileri, iç iletişim verileri ve şirketin kendi iletişim kanallarından oluşan geri bildirimler, kamuya açık paylaşımlı veriler, deneysel pazarlama verileri, etkinlik ve sponsorluklardan kaynaklanan halkla ilişkiler verilerinden oluşmaktadır. Bu veriler birçok halka ilişkiler şirketinin en önemli varlıkları arasındadır. $\mathrm{Bu}$ verilere ek olarak haber kanallarından, sosyal medyadan ve rakiplerin pazarlama ve tanıtım faaliyetlerinden gelen veriler de bulunmaktadır (Mark Weiner, 2016). Özellikle sosyal medya üzerinden yapılan tanıtım, pazarlama ve halkla ilişkiler kampanyalarının teknolojik olarak izlenebilir ve elde edilebilir olması sonucu daha doğru ve konumlandırılmış veriler ve istatistikler alınabilmektedir (Wright ve Hinson, 2008). Bu veriler hedef kitlelerin davranış ve tercihlerinin analizinde kullanılabileceği gibi bilgi, tutum ve davranışlarda değişiklik yaratma, farkındalığı artırma, kurumsal sosyal sorumluluk faaliyetleri, kriz yönetimi, imaj yönetimi, itibar yönetimi, sosyal medya yönetimi vb. alanlarda halkla ilişkiler stratejileri geliştirmek için kullanılabilmektedir.

Halkla ilişkiler çalışmalarında sadece bir piyasa ve ürün ile ilgili çoğunlukla nicel, kategorik verilerden oluşan anket veya içerik analizi yapıldığında neler olduğuna dair bir gözlem raporu oluşturulabilir. Bu gözlemlerin tesadüfen mi meydana geldiği, müşteri kitlesindeki farklılıklardan $\mathrm{m} 1$ ortaya çıktığ 1 yada araştırmaya konu olan bir hipotezin doğruluğu sonucu mu oluştuğu ise çıkarımsal istatistik ile incelenebilmektedir (Stacks, 2016) Çıkarımsal istatistikler kalıpları, korelasyonları veya eğilimleri ortaya koyarak halkla ilişkiler stratejilerinin oluşturulmasında kullanılabilmektedir (Jugenheimer et al., 2015; Stacks, 2016)

$\mathrm{Bu}$ kadar veri odaklı bir topluma dönüşürken verilerin kişiselliği ve güvenliği de önemli bir kavram haline gelmiştir. Bireyler artık kişisel verilerinin korunması konusunda daha bilinçli ve duyarlı hale gelmeye başlamıştır. Özellikle sosyal medya ve ücretsiz haberleşme uygulamalarının arka planda veri toplamaya çalışması, bu veriler ile ilgili bazı ticari faaliyetlerde bulunması yönündeki politika değişiklikleri bu hizmeti sunan firmaların pazardaki paylarının bile oynamasına neden olmaya başlamıştır. 2021 yılında Facebook firması çatısı altında faaliyet gösteren WhatsApp anlık haberleşme uygulamasının veri işleme politikalarında düzenleme yapacağını açıklaması ve kullanıcıların buna tepkisi iyi bir örnek olarak gösterilebilir (Wijoyo et al., 2021). Sonraki günlerde alternatif uygulamalar ile yapılan veri kullanım karşılaştırmaları uzun sürecek bir bakış açısı farklılıklarının ve kişisel veri güvenliğinin önemini ortaya koymuştur (Sindermann et al., 2021).

Elde edilen verilerin saklanması, korunmas1, sadece verinin sahibi ve yetki verdiği taraflarca görünmesi, kullanılması, değiştirilmesi, işlenmesi kavramlarını içeren veri yönetişimi kavramı da bu süreçler ile birlikte gelişmekte ve bu konuda birçok çalışma yapılmaktadır (Alhassan et al., 2016; Khatri \& Brown, 2010; Ladley, 2019). Veri yönetişimi içerisindeki önemli başlıkları veriye dijital ve fiziksel olarak erişmek ile ilgili oluşturulmuştur. Bu kapsamda yapılan çalışmalar özellikle sağlık, askeri ve ticari şirket verilerinin yönetişimi ile ilgili yapılmaktadır (Rosenbaum, 2010). Yönetişim süreçleri ile ilgili çeşitli kavramsal çerçevelerde bu süreçlere paralel olarak geliştirilmektedir (Abraham et al., 2019).

Güvenilir iletişim, veri paylaşımı ve veri taşıması ile ilgili çalışmalar 1980'lere dayanmaktadır. (Shamir et al., 1981; Yao, 1986). Geliştirilmeye başlanan farklı protokoller o yıllar için çok temel ve kavramsal olsa da günümüzdeki büyük ve bulut bilişim platformları ile ilgili veri paylaşım ortamları için kaynak teşkil etmektedir (Yao, 1982).

Veri paylaşımı, halkla ilişkiler alanında karşılaşılan iş zorluklarını çözmek ve kurumsal hedeflere ulaşmak için daha sağlam veriler oluşturarak, kurum ve kampanya amaçları ile daha yakından ilgili verileri optimize etmenin bir yoludur. Bilim ve araştırma için parasal yatırımın azaldığı dönemlerde veri paylaşımı araştırmacıların kaynakları paylaşmasına olanak tanıyarak verimliliği artırabilir. Halkla ilişkiler ve kurumsal iletişim ajansları kendi aralarında, hizmet verdikleri şirketlerle aralarında ya da farklı aracı kuruluşlarla veri paylaşımı yapabilirler. Veri paylaşımı, uzmanlar arasında daha güçlü bağlantıları ve işbirliğini teşvik etmekte; bu da halkla ilişkiler alanında önemli yeni bulgulara, daha etkili iş sonuçlarına yol açabilmektedir. Goasduff (2021) kurumlar arası veri paylaşımının, etkin paydaş katılımını ve kurumsal değer 
sağlamanın işle ilgili önemli bir performans göstergesi olduğunu bildirmekte; 2023 yılına kadar veri paylaşımını destekleyen kuruluşların iş sonuçları ölçümünde emsallerinden daha iyi performans göstereceğini tahmin etmektedir.

\section{Malzeme ve Yöntem}

\subsection{Veri Seti ve Problem Tanımı}

Halkla İlişkiler şirketlerinin veri analizi ve işlemesi ile ilgili oluşturulan üç senaryoya uygun olarak modüller entegre edilmiştir. Entegre edilen modüller geliştirmeye açık ve uygun kullanıcı ara yüzleri ile zenginleştirilecek şekilde modellenmiştir. İlk senaryo Çok Taraflı Hesaplama başlığında, ikinci ve üçüncü senaryolar ise Homomorfik Şifreleme başlığında makine öğrenmesiyle birlikte ele alınmıştır.

Testlerde kullanmak için kullanılan veri seti birçok makine öğrenmesi probleminde örnek olarak kullanılan telekom şirketlerinin churn müşteri sadakat analizi veri setidir (JafariMarandi et al., 2020). Bu veri seti ile ilgili birçok karşılaştırmalı analiz hali hazırda yapılmış ve yapısal olarak iyi bir veri seti olduğu kabul edilmiştir hatta demo veri seti olarak makine öğrenmesi kütüphanelerine eklenmiştir (Vafeiadis et al., 2015).

3150 kayıttan oluşan veri seti hayali olarak üç rastgele dengeli bölüme ayrılmış ve hayali olarak bu verilerin $A, B$ ve $C$ halkla ilişkiler şirketinin elindeki anket ve analiz verileri olduğu varsayılmıştır. Sektördeki bu üç hayali şirketin ellerindeki verileri birbirleri ile doğrudan açık bir şekilde paylaşmadan analiz edebilecekleri bir senaryo ile bu halkla ilişsiler şirketlerinden yeni çıkaracakları bir ürün ile ilgili en uygun portföye ve analiz verilerine sahip şirketi seçecek bir hizmet almak isteyen telekom operatörünün makine öğrenmesi sınıflandırma ve segmentasyon ihtiyacına verileri şifreli bir şekilde işleyebileceği bir senaryo düşünülmüştür. Veri işleme senaryosunda $\mathrm{kNN}$ ve karar destek ağaçları algoritmalarının kullanılacağı varsayılmıştır.

\section{2. Çok Taraflı Hesaplama}

Güvenli Çok Taraflı Hesaplama (Secure Multi Party Computation) ya da Mahremiyeti Koruyan Hesaplama (Privacy Preserving Calculation) yaklaşımları iletişim araçlarının artması ve ortak veri işleme ihtiyaçlarının artmasıyla birlikte öne çıkmaktadır. Temel olarak hesaplama yapacak olan paydaşların, hesaplamalarda kullanılacak olan veri setlerini ve verileri bir fonksiyon üzerinde paylaşmaları sistematiğine dayanmaktadır. Taraflar verilerin kimden ve hangi seviyede geldiğini bilmeden temel matematiksel hesapları yapabilmektedirler. Verilerin fonksiyonlar üzerinden paylaşılması tüm tarafların kullanabileceği bir şifreleme sistemi ile de korunabilir.

Bilgi teknolojileri alanındaki birçok çalışmanın temelinde uygulama ve test etmesi kolay olduğu ve risk içermediği için kullanılan oyun ve simülasyonlar üzerinden konuşulmaya başlanmıştır. 1970'lerdeki uzak mesafedeki iki paydaşın güvenli bir şekilde bir kart oyunu oynayabilmelerini kurgulayan güvenli poker oynama algoritması bu konudaki ilk çalışma olarak kabul edilebilir (Shamir et al., 1981). Sonrasında bilgisayar sistemlerinin ortak hesaplama yapmasını modelleyen çalışmalar ile gelişmeye devam etmiştir (Yao, 1982, 1986). Bu algoritmaların tüm tarafların dürüst hareket ettiği ve kötü niyetli bir şekilde sistemin zaafiyetlerini kullanarak sisteme saldırmayacakları üzerine kurulmuştur ve yapılan protokol güncellemeleri ile belli bir seviyeye kadar birden fazla kullanıcının birlikte hareket etmesi veya kullanıcı hataları sonucu ortaya çıkabilecek açıkları tolere edebilmesine dayanmaktadır (Dolev et al., 1993). Günümüzde geliştirilmiş olan temel paylaşım şemaları bu sorunları ortadan kaldıran güncel şemaların oluşmasını sağlamıştır (Goldreich et al., 2019).

Çok taraflı hesaplama sistemlerinde sistemin güvenliği veri aktarımında kullanılan fonksiyonların seviyeleri arttığında gerekli olan hesaplama işlemlerinin ihtiyaç duyduğu yüksek işlemci gücü nedeni ile uzun yıllar boyunca verimsiz ve kullanmanın pratik olmadığı uygulamalar olarak tanımlanmasına neden olmuştur. Ancak sonraki yıllarda yapılan geliştirme ve çalışmalar verimli algoritmalar oluşmasını sağlamış bu algoritmaların da bulut bilişim gibi ortamlarda kullanılabilmesi ile son kullanıcı tarafindan kullanılabilmesine imkân sağlamıştır (Abascal et al., 2020).

Sonraki yıllarda dağıtılmış oylama, özel teklif verme ve açık artırmalar, müzayede satışları (Dinakaran, n.d.), imza paylaşımı gibi uygulamalarda başarı ile kullanılmıştır (Bendlin et al., 2011).

\subsection{Homomorfik Şifreleme}

Şifreleme ile ilgili çalışmalar matematiksel yaklaşımlarıyla birlikte pratik olarak veri gizliliğinin en önemli olduğu askeri sistemlerde kullanılmış ve gelişmiştir (Shannon, 1949). Alan Turing'in ikinci dünya savaşından Alman silahlı kuvvetleri tarafından şifreli haberleşme amacı ile kullanılan Enigma cihazının şifresini kırmasıyla birlikte savaş sonrası dönemlerde şifreleme ve güvenli veri iletimi önemli bir sürece girmiştir. (Turing, 2004) Temel olarak şifreleme, düz metni koda veya okunamayan metin biçimine dönüştürmek için uygulanan algoritmaları ifade etmektedir (Goldwasser ve Micali, 1984). Düz metnin şifrelenmesi ve sonrasında şifrelenmiş metnin alıcısı tarafindan çözülmesi için kullanılan "anahtar" yapıları ve algoritmalarına göre yıllar içerisinde gelişmeye devam etmiştir (Biham ve Shamir, 1991). Günümüzde çalışmalar daha çok sistemlerin güvenliğini yüksek hesaplama gücüne sahip kuantum bilgisayarların yaygınlaşması sonrasında nasıl korunacağı ile ilgili süreçlerle ve verilerin bulut sistemleri üzerinde güvenli olarak işlenebilmesine odaklanmıştır (L. Chen et al., 2016).

Bulut hizmetlerinin kullanmanın olası dezavantajlarının başında herhangi bir saldırı ve ihlal olduğunda ele geçen verilere ait mahremiyet kayıpları ve gizli verilerin ticari değeridir. $\mathrm{Bu}$ sorunlarla başa çıkmanın pratik bir yöntemi, bulutta depolanan tüm verileri şifrelemek ve şifrelenmiş veriler üzerinde matematiksel işlemler gerçekleştirmektir. Şifre çözme yapıldığında şifrelenmiş sonuç aynı kalacaktır. $\mathrm{Bu}$ amaçla geliştirilen şifrelenmiş veriler üzerine işlem yapabilen homomorfik şifreleme algoritmaları, temel olarak uygun bir şema seçimi ile kurulum, gizli anahtar, genel anahtar, yeniden doğrusallaştırma anahtarı gibi anahtar oluşturma işlemleri, şifreleme, değerlendirme aşamalarından oluşmaktadır (Bozduman ve Afacan, 2020).

Homomorfik şifreleme, şifreli metinlerde hesaplama yapılmasına olanak sağlayan ve şifresi çözüldüğünde düz metin üzerinde yapılmış gibi işlemlerin sonucuyla eşleşen şifreli bir sonuç üreten bir şifreleme yöntemidir. Basit Şifreli Aritmetik Kitaplığı SEAL, Microsoft tarafından geliştirilmiş homomorfik bir şifreleme kitaplığıdır. (H. Chen et al., 2017) The Brakerski/Fan-Vercauteren BFV (Fan ve Vercauteren, 2012) ve Cheon, Kim, Kim ve Song CKKS (Cheon et al., 2017) gibi çok başka özelliklere sahip iki farklı homomorfik şifreleme şemasıyla birlikte gelmektedir. BFV şeması, şifrelenmiş veriler üzerinde modüler aritmetik yapılmasına izin verirken CKKS şeması, 
şifrelenmiş gerçek veya karmaşık sayılar üzerinde toplamalara ve çarpmalara izin verir, ancak yalnızca yaklaşık sonuçlar vermektedir (Mert et al., 2019).

\section{Bulut Tabanlı Güvenli Çok Taraflı Hesaplama ve İş birliği Servisi - SMPCCaaS}

Kavramsal, mantıksal ve fiziksel modeli oluşturulan servisin bulut bilişim üzerinde konumlandırılması, self servis, esnek ölçeklendirme ve kullandıkça öde yaklaşımı ile çalışması hedeflenmiştir. Seçilen teknolojiler açık kaynak kodlu ek lisans maliyeti gerektirmeyen yazılım ve kütüphanelerden oluşturulmuş aynı zamanda uygulama repoları ile güncel kalmasını sağlanmıştır.

Tanımlanan iş modeli içerisinde şirketlerin kendi şifreleme anahtarları ile verileri şifreleyip bulut servislerine aktarabilmeleri, bu veriler üzerinden şifreli işlem yapacak olan hizmet alacak firmaların test verisetlerini açık olarak sisteme yükledikten sonra ilgilenen firmaların bu veri setlerini kendi müşteri verileri ile karşılaştırma yapabilecekleri bir akış kurgulanmıştır. Aynı şekilde anahtar üretilmesi ve saklanması hizmetini bulut servisi kapsamında alabilecekleri bir akış da kurgulanmıştır. Teknik olarak bulut servisini verecek olan hizmet sağlayıcı ve halkla ilişkiler şirketleri arasında imzalanacak olan NDA gizlilik anlaşması kapsamında bu hizmetlerin kapsamı belirlenmesi, SLA hizmet seviyesi anlaşması ile de servisin hizmet kapsamının belirlenmesi yapılacaktır.

Sistemdeki kodların geliştirilmesi Python kullanılmıştır. Ana geliştirmeler ve testler için Google Colab ücretsiz versiyon kullanılmıştır. Yaygınlaştırma için sonrasında bulut bilişimdeki sanal makineye kurulum yapılmıştır (Google, 2021).

\subsection{Sanal Makine Altyapısı}

Uygulamanın bulut bilişim üzerinde esnek ve ölçeklenebilir olarak çalışması için sanal makineler üzerine kurulum yapılmıştır. $\mathrm{Bu}$ açıdan Microsoft, Amazon, Google, Alibaba, IBM gibi şirketlerin benzer hizmetleri bulunmaktadır. İhtiyaç duyulan Python altyapısı marka bağımlılığı olmadan kullanılabildiğinden farklı bir servis ile de çözüm üretilebilir. Mevcut sistemde geliştirilen kodlar öncelikle Amazon EC2 bulut sunucusuna aktarılmıştır. Amazon Web Services (AWS) altyapısında uygulamaları çalıştırmak için Amazon'un Elastic Compute Cloud'unda (EC2) bulunan bir sanal sunucudur. Pratik olarak sınırsız sayıda sanal makine (VM) olarak hizmet edebileceğinden ölçeklenebilir olması sağlanmıştır. (Amazon, 2021) Yapılan geliştirme ve modüller farklı sektörel uygulamalar için de kullanılabilecektir.

\section{2. Çok Taraflı Hesaplama Modülü}

Uygulama senaryoları olarak halkla ilişkiler şirketlerinin ellerindeki verileri ortak istatistiksel hesaplamalar yapabilecekleri çok taraflı hesaplama modülü MPyC for Secure Multiparty Computation kütüphanesi entegre edilmiştir (Schoenmakers, 2021). Senaryo çalışmalarına göre sektörel olarak A, B ve C firmalarının ellerindeki verileri sistem üzerinden paylaşarak müşteri şikayetleri, arama sırasındaki sistemsel hatalar, abonelik süreleri, ortalama fatura ve ücretlendirme miktarları, fatura tipleri, arama sıklıkları, müşterinin karlılı̆̆ kullanımları ve müşterinin şikayetler sonucunda firmadan vazgeçmesi (churn) gibi veriler matematiksel olarak ortalamalar alınmıştır. Sistem üzerinde girilen veriler ile ortalama, medyan, varyans ve standart sapma gibi temel istatistiki analizler yapilabilmektedir.

\subsection{Güvenli Eşleştirme Modülü}

TenSEAL: A Library for Encrypted Tensor Operations Using Homomorphic Encryption kütüphanesi Python ile geliştirilmiş açık kaynak kodlu bir kütüphanedir (Benaissa et al., 2021) TENSEAL, Microsoft SEAL üzerine inşa edilmiş, tensörler üzerinde homomorfik şifreleme işlemleri gerçekleştirmek için bir kitaplıktır. (H. Chen et al., 2017) İşlemlerinin çoğunu C++ kullanarak uygulayarak performansı korurken, bir Python API aracılığıyla kullanım kolaylığı sağlar (Halevi et al., 2019).

Müşteri havuzlarındaki hizmet almak isteyen şirketlerin ellerindeki hedef kitleye yakın kitleler ile ilgili yapılacak halkla ilişkiler faaliyetleri için benzer veri setlerindeki müşteri verilerinin analizinde kullanılması hedeflenmiştir. Müş̧teri veri vektörlerindeki vektörel uzaklıkların kullanılması hedeflenmiştir. TenSEAL kütüphanesi vektör çarpımları ve Öklid vektör uzaklıklarının hesaplanmasında kullanılmak üzere entegre edilmiştir. Hizmet almak isteyen firmalar hedef müşteri vektörlerini sisteme yükleyerek benzer veriye ve hizmete sahip halkla ilișkiler şirketlerinin verilerinin analizi yapabilecek ve bu analizlere göre faaliyet planlaması yapabileceklerdir.

\subsection{Güvenli Makine Öğrenmesi Modülü}

Hedef kitle müşterileri ile ilgili yapılacak olan sınıflandırma ve segmentasyon analizleri için makine öğrenmesi algoritmaları kullanılması düşünülmüştür. Homomorfik şifreleme güvenli ama hesaplama olarak her matematiksel hesaba uygun olmadığından temel sınıflandırma algoritmaları tercih edilmiştir. Burada halkla ilişkiler firmalarının veri setlerinin karmaşıklıktan çok güvenli işlenmesi gereken kişisel veriler ve ticari bilgi varlıkları olmasından dolayı yöntemler zaten iyi sonuçlar verdiği literatürdeki örneklerde bulunmaktadır (Alawaad, 2021; Biswal, 2020). Bu amaçla kNN gibi vektör uzaklıklarına dayalı hesaplamalar için TenSEAL ve karar ağaçları uygulamaları için ise Cryptotree (Huynh, 2020) kütüphanesini kullanmaktadır.

\section{Sonuç ve Öneriler}

Veri, stratejik iletişimin etkilerine dair yeni anlayışlar sağladığı için, kurumlar her tür veriyi kurumsal iletişimlerini geliştirmek için kullanabilirler. Kurumlar için neyin önemli olduğunu bilmek ve önemli olanı ölçmek; büyük veriyi karar mekanizmalarında kullanmak üzere dönüştürebilmek ve veri paylaşımı şirketlerin gelecekteki iletişim süreçleri için önceliklidir. Daha önceleri yüz yüze toplantılar, telefon görüşmeleri, taşınabilir cihazlar ya da e-mailler ile belli endişeler ile paylaşılan veriler, günümüzde paylaşılacak/kurumun kendisine saklanacak bilgiyi tanımlama imkanı ile sanal ortamda güvenli olarak paylaşılabilmektedir. Veri paylaşımı bilgilerin paylaşılması ve anlaşılması için esas olmanın yanı sıra kurumlar arasında iki yönlü diyalog ve geri bildirim döngüsünün arttırılmasına katkı sağlamaktadır. Araştırmalar için bütçeler kesildiğinde, veri paylaşımı, araştırmacıların ve uzmanların kaynakları bir araya getirmesine izin vererek üretkenliği artırabilir. Halkla ilişkiler ve kurumsal iletişim ajansları kendi aralarında; hizmet verdikleri kurumlarla veya etkinlik ajansları, medya ajansları ve rekllam ajansları gibi çözüm ortaklarıyla çok taraflı veri paylaşımında bulunabilirler. Veri paylaşımı, halkla 
ilişkiler alanında etkili sonuçlara ulaşmanın yanı sıra ajanslar ve uzmanlar arasında daha iş birliğini teşvik edebilmektedir.

$\mathrm{Bu}$ çalışmada yeni nesil halkla ilişkiler yaklaşımları çerçevesinden ajanslar ve uzmanlar tarafindan ihtiyaç duyulan güvenli veri analizi, iş birliği ve ortak hesaplama yaklaşımlarına destek verecek bir bulut bilişim servisinin mimarisi ve yapısı anlatılmıştır. Önerilen sistem ticari olarak ön yüz ve kullanıcı dostu kod geliştirmelerine ihtiyaç duyan kavramın ispatı PoC kapsamında yapılmıştır. Veri güvenliği ve veri yönetişimi açısından saklanan ve işlenen verilerin gizliliğini, sorguların gizliliğini ve veri yapılarına doğrudan erişmeyi engelleyen bir yapıdadır. Yapılacak olan hesaplamalar halkla ilişkiler süreçlerindeki kampanya ve etkinlik dönemlerinde kullanılacağından anlık ve sürekli ihtiyaç oluşturmamaktadır. $\mathrm{Bu}$ nedenle homomorfik şifreleme ve güvenli çok taraflı hesaplama süreçlerinde en önemli sorunlardan biri olan hesaplamalarda ihtiyaç duyulan yüksek işlemci gücü ihtiyacı bulut bilişim servislerinde kullandıkça öde modeli içerisinde karşılanacak ve hizmetin servis olarak sunulması ilk yatırım ve işletme maliyetlerini en aza indirecektir. Sistem halkla ilişkiler ekosistemi içerisinde verinin değerinin hem müşteri hem de hizmet verenler açısından daha değerli bir varlık olarak kullanılması sağlamaktadır.

İlerleyen zamanlarda hizmetin Topluluk Bulutu (community cloud) kapsamında Türkiye Halkla İlişkiler Derneği gibi meslek kuruluşları ile yerinde hizmet kapsamında (on premise) modeli ile konteyner mimarisi içerisinde sunulabilmesi hedeflenmiştir.

\section{Kaynakça}

Abascal, J., Faghihi Sereshgi, M. H., Hazay, C., Ishai, Y., ve Venkitasubramaniam, M. (2020). Is the Classical GMW Paradigm Practical? The Case of Non-Interactive Actively Secure 2PC. Proceedings of the 2020 ACM SIGSAC Conference on Computer and Communications Security, 1591-1605.

Abraham, R., Schneider, J., ve vom Brocke, J. (2019). Data governance: A conceptual framework, structured review, and research agenda. International Journal of Information Management, 49, 424-438.

https://doi.org/10.1016/J.IJINFOMGT.2019.07.008

Alawaad, H. A. (2021). The role of Artificial Intelligence (AI) in Public Relations and Product Marketing in Modern Organizations. Turkish Journal of Computer and Mathematics Education (TURCOMAT), 12(14), 3180-3187.

Alhassan, I., Sammon, D., ve Daly, M. (2016). Data governance activities: an analysis of the literature. Journal of Decision Systems, 25(sup1), 64-75.

Amazon. (2021). Amazon EC2. In Amazon Web Services, Inc. https://aws.amazon.com/ec2/

Baars, H., ve Kemper, H.-G. (2008). Management support with structured and unstructured data-an integrated business intelligence framework. Information Systems Management, 25(2), 132-148.

Barnett, M. L., Jermier, J. M., ve Lafferty, B. A. (2006). Corporate reputation: The definitional landscape. Corporate Reputation Review, 9(1), 26-38.

Baygül Özpınar, Ş. B. (2021). "Yeni”" Teknolojiler ve Kurumsal İletişimin Yeni Araçları. Etkileşim, 7, 150-168.

Baygül Özpınar, Ş. B. (2018). Kurumsal itibarın ölçümü: Türkiye'ye yönelik ölçek geliştirme çalışması. Ed. Metin Reyhaoğlu, Araştırmalar Işı̆̆ıda Yönetimde Güncel Konular,
474-464. Nobel.

Benaissa, A., Retiat, B., Cebere, B., ve Belfedhal, A. E. (2021). TenSEAL: A Library for Encrypted Tensor Operations Using Homomorphic Encryption. ArXiv Preprint ArXiv:2104.03152.

Bendlin, R., Damgård, I., Orlandi, C., ve Zakarias, S. (2011). Semi-homomorphic encryption and multiparty computation. Annual International Conference on the Theory and Applications of Cryptographic Techniques, 169-188.

Biham, E., ve Shamir, A. (1991). Differential cryptanalysis of DES-like cryptosystems. Journal of CRYPTOLOGY, 4(1), 3 72.

Biswal, S. K. (2020). The Space of Artificial Intelligence in Public Relations: The Way Forward. In Optimization in Machine Learning and Applications (pp. 169-176). Springer.

Bozduman, H. Ç., ve Afacan, E. (2020). Simulation of a Homomorphic Encryption System. Applied Mathematics and Nonlinear Sciences, 5(1), 479-484.

https://doi.org/10.2478/amns.2020.1.00046

Brown, R. E. (2010). Symmetry and its critics: Antecedents, prospects and implications for symmetry in a postsymmetry era. The SAGE Handbook of Public Relations, 277-92.

Bulao, J. (2021). How Much Data Is Created Every Day in 2021? In TechJury. https://techjury.net/blog/how-much-data-iscreated-every-day/

Chen, H., Laine, K., ve Player, R. (2017). Simple encrypted arithmetic library-SEAL v2. 1. International Conference on Financial Cryptography and Data Security, 3-18.

Chen, L., Chen, L., Jordan, S., Liu, Y.-K., Moody, D., Peralta, R., Perlner, R., ve Smith-Tone, D. (2016). Report on postquantum cryptography (Vol. 12). US Department of Commerce, National Institute of Standards and Technology.

Cheon, J. H., Kim, A., Kim, M., ve Song, Y. (2017). Homomorphic encryption for arithmetic of approximate numbers. International Conference on the Theory and Application of Cryptology and Information Security, 409437.

Chun, R. (2005). Corporate reputation: Meaning and measurement. International Journal of Management Reviews, 7(2), 91-109.

Cutlip, Scott (1994). The Unseen Power: A History of Public Relations. Lawrence Erlbaum Associates.

Demchenko, Y., De Laat, C., ve Membrey, P. (2014). Defining architecture components of the Big Data Ecosystem. 2014 International Conference on Collaboration Technologies and Systems (CTS), 104-112.

Dinakaran, S. S. (n.d.). An Overview on Secured Multi-Party Computations (SMC).

Dolev, D., Dwork, C., Waarts, O., ve Yung, M. (1993). Perfectly secure message transmission. Journal of the ACM (JACM), $40(1), 17-47$.

Fan, J., ve Vercauteren, F. (2012). Somewhat practical fully homomorphic encryption. IACR Cryptol. EPrint Arch., 2012, 144.

Fox, M. (2021). Zoom overtakes Exxon Mobil in market value amid COVID-19 pandemic. In Business Insider. https://www.businessinsider.com/zoom-exxon-mobilovertakes-market-value-stock-price-covid19-pandemic2020-10

Goasduff, L. (2021). Data sharing is a business necessity to accelerate digital business.

https:/www.gartner.com/smarterwithgartner/data-sharing-is-abusiness-necessity-to-accelerate-digital-business 
Goldreich, O., Micali, S., ve Wigderson, A. (2019). How to play any mental game, or a completeness theorem for protocols with honest majority. In Providing Sound Foundations for Cryptography: On the Work of Shafi Goldwasser and Silvio Micali (pp. 307-328).

Goldwasser, S., ve Micali, S. (1984). Probabilistic encryption. Journal of Computer and System Sciences, 28(2), 270-299.

Google. (2021). Google Colaboratory. https://colab.research.google.com/

Gotsi, M., ve Wilson, A. M. (2001). Corporate reputation: seeking a definition. Corporate Communications: An International Journal.

Grunig, J. E., ve Grunig, L. A. (1992). Models of public relations and communication. Excellence in Public Relations and Communication Management, 1992, 285-325.

Halevi, S., Polyakov, Y., ve Shoup, V. (2019). An improved RNS variant of the BFV homomorphic encryption scheme. Cryptographers' Track at the RSA Conference, 83-105.

Harrison, G. (1953). Public Relations. YB, 65.

Hirsch, D. D. (2013). The glass house effect: Big Data, the new oil, and the power of analogy. Me. L. Rev., 66, 373 .

Huynh, D. (2020). Cryptotree: fast and accurate predictions on encrypted structured data. ArXiv Preprint ArXiv:2006.08299.

Johnson, M. A. (1997). Public relations and technology: Practitioner perspectives. Journal of Public Relations Research, 9(3), 213-236.

Jugenheimer, D. W., Kelley, L. D., Hudson, J., ve Bradley, S. (2015). Advertising and public relations research. Routledge.

Kacen, J. J., Hess, J. D., ve Chiang, W. K. (2013). Bricks or clicks? Consumer attitudes toward traditional stores and online stores. Global Economics and Management Review, 18(1), 12-21.

Khatri, V., ve Brown, C. V. (2010). Designing data governance. Communications of the ACM, 53(1), 148-152.

Kim, Y. (2001). Measuring the economic value of public relations. Journal of Public Relations Research, 13(1), 3-26.

Kiousis, S., Popescu, C., ve Mitrook, M. (2007). Understanding influence on corporate reputation: An examination of public relations efforts, media coverage, public opinion, and financial performance from an agenda-building and agendasetting perspective. Journal of Public Relations Research, 19(2), 147-165.

Ladley, J. (2019). Data governance: How to design, deploy, and sustain an effective data governance program. Academic Press.

Laudon, K. C., ve Laudon, J. P. (2011). Essentials of management information systems.

Ljungqvist, A., ve Wilhelm Jr, W. J. (2003). IPO pricing in the dot-com bubble. The Journal of Finance, 58(2), 723-752.

Manyika, J., Chui, M., Brown, B., Bughin, J., Dobbs, R., Roxburgh, C., ve Hung Byers, A. (2011). Big data: The next frontier for innovation, competition, and productivity. McKinsey Global Institute.

Mark Weiner, S. K. (2016). Irreversible: The Public Relations Big Data Revolution. Institute for Public Relations. https://instituteforpr.org/wp-content/uploads/IPR_PR-BigData-Revolution_3-29.pdf

Mert, A. C., Öztürk, E., ve Savaş, E. (2019). Design and implementation of encryption/decryption architectures for bfv homomorphic encryption scheme. IEEE Transactions on Very Large Scale Integration (VLSI) Systems, 28(2), 353-362.

Newsom, D., Turk, J., ve Kruckeberg, D. (2012). Cengage advantage books: This is PR: The realities of public relations.
Cengage Learning.

Ofek, E., Katona, Z., ve Sarvary, M. (2011). "Bricks and clicks": The impact of product returns on the strategies of multichannel retailers. Marketing Science, 30(1), 42-60.

PRSSA. (n.d.). What is public relations: Learn about PR. Erişim 23 Ekim, 2021, https:/www.prsa.org/reference/prssa/aboutprssa/learn-about-pr.

Özgen, E., ve Bilbil, E. (2007). Türkiye'de ulusal basın ile ilişkiler kapsamında halkla ilişkiler ve reklamcıların etik sorunları. Marmara İletişim Dergisi, 12(12), 177-185.

Rosenbaum, S. (2010). Data governance and stewardship: designing data stewardship entities and advancing data access. Health Services Research, 45(5p2), 1442-1455.

Schoenmakers, B. (2021). $M P y C$.

https://www.win.tue.nl/ berry/mpyc/

Seitel, F. P. (2017). Practice of public relations. Pearson Education.

Shamir, A., Rivest, R. L., ve Adleman, L. M. (1981). Mental poker. In The mathematical gardner (pp. 37-43). Springer.

Shannon, C. E. (1949). Communication theory of secrecy systems. The Bell System Technical Journal, 28(4), 656-715.

Sindermann, C., Lachmann, B., Elhai, J. D., ve Montag, C. (2021). Personality associations with WhatsApp usage and usage of alternative messaging applications to protect one's own data. In Journal of Individual Differences ( $p$. No Pagination Specified-No Pagination Specified). Hogrefe Publishing. https://doi.org/10.1027/1614-0001/a000343

Stacks, D. W. (2016). Primer of public relations research. Guilford Publications.

Taşçı, M. E. \& Şamlı, R. (2020). Veri Madenciliği İle Kalp Hastalığı Teşhisi. Avrupa Bilim ve Teknoloji Dergisi, (Özel Say1), 88-95.

Turing, A. M. (2004). The essential turing. Oxford University Press.

Wang, F. (2014). Field Study of Patent Strategies from Patent Map on Big Data: An Empirical Case of Big Data Application Platform in Taiwan.

Whitten, D., ve Leidner, D. (2006). Bringing IT back: An analysis of the decision to backsource or switch vendors. Decision Sciences, 37(4), 605-621.

Wiencierz, C., ve Röttger, U. (2019). Big Data in Public Relations: A Conceptual Framework. 12, 1-15.

Wijoyo, H., Limakrisna, N., ve Suryanti, S. (2021). The effect of renewal privacy policy whatsapp to customer behavior. Insight Management Journal, 1(2), 26-31.

Wilcox, D. L., Ault, P. H., ve Agee, W. K. (2006). Public relations: Strategies and tactics.

Wright, D. K., ve Hinson, M. D. (2008). How blogs and social media are changing public relations and the way it is practiced. Public Relations Journal, 2(2), 1-21.

Yao, A. C.-C. (1982). Protocols for Secure Computations (Extended Abstract) BT - 23rd Annual Symposium on Foundations of Computer Science, Chicago, Illinois, USA, 35 November 1982 (pp. 160-164).

https://doi.org/10.1109/SFCS.1982.38

Yao, A. C.-C. (1986). How to Generate and Exchange Secrets (Extended Abstract) BT - 27th Annual Symposium on Foundations of Computer Science, Toronto, Canada, 27-29 October $1986 \quad$ (pp. 162-167). https://doi.org/10.1109/SFCS.1986.25

Zhang, Y., Ren, J., Liu, J., Xu, C., Guo, H., ve Liu, Y. (2017). A survey on emerging computing paradigms for big data. Chinese Journal of Electronics, 26(1), 1-12. 